\title{
Pendeteksi Wajah Secara Real Time pada 2 Degree of Freedom (DOF) Kepala Robot Menggunakan Deep Integral Image Cascade
}

\author{
Dwi Agung Al Ayubi ${ }^{1}$, Dwi Arman Prasetya ${ }^{2}$, dan Irfan Mujahidin ${ }^{3 *}$ \\ 1,2,3 Program Studi Teknik Elektro, Universitas Merdeka Malang \\ 1,2,3 Jl. Taman Agung, Karangbesuki, Kec. Sukun, Kota Malang, Jawa Timur 65146 \\ e-mail: dwiagung20april1995@gmail.com
}

\begin{abstract}
Abstrak - Teknologi Robot merupakan karya terbaik yang sangat penting bagi kehidupan manusia modern saat ini untuk mempermudah semua pekerjaan manusia. Perkembangan dunia robot saat ini akan difokuskan pada robot yang memiliki fitur mirip manusia. Bahkan diharapkan memiliki kemampuan berinteraksi dan berperilaku seperti manusia yaitu robot humanoid, mekanisme dari gerakan robot humanoid memiliki derajat kebebasan Degree of Freedom (DOF). Layaknya pada manusia robot diberi kemampuan penglihatan untuk mendeteksi adanya objek yang ditangkap secara real time Penelitian kepala robot 2 degree of freedom (DOF) untuk pendeteksi wajah secara real time menggunakan metode Deep Integral Image Cascade untuk deteksi wajahnya. Untuk keakurasian pendeteksi wajah dengan real time pada penelitian ini dengan pengujian akurasi terbesar adalah 95,25\% dengan waktu respons pendeteksi tercepat 7 detik dengan waktu terlama 8,55 second rata-rata data citra semuanya tidak terdeteksi dengan benar
\end{abstract}

Kata kunci : Raspberry pi, Pendeteksi wajah, Degree of freedom, Haar cascade classifier, Robot kepala

Abstract-Robot technology is the best work that is very important for modern human life today to facilitate all human work. The development of the robot world today will be focused on being a robot that has human-like features. Even expected to have the ability to interact and behave like a humanoid robot, the mechanism of humanoid robot movement has a degree of freedom of Degree of Freedom (DOF). Like in the robot man is given the ability of vision to detect the presence of objects captured in real time robotic head Research 2 degree of freedom (DOF) for face detection in real time using the Deep Integral Image Cascade method to Face Detection. For the real-time accuracy of the face detector in this research with the greatest precision testing is $95.25 \%$ with the fastest detection response time of 7 seconds with the oldest time 8.55 second the average image data everything is not detected with Really.

Keywords: Raspberry Pi, face detector, Degree of freedom, Haar Cascade classifier, Robot head

\section{PENDAHULUAN}

Kepala adalah bagian dari tubuh manusia yang memiliki telinga, hidung, mulut, dan mata yang berfungsi sebagai tanda pengenal orang, wajah juga biasa disebut dengan bagian depan dari kepala. Pada umumnya wajah digunakan untuk interaksi dua arah terhadap lawan bicara pada kehidupan manusia ini menunjukkan interaksi komunikasi yang baik[1].

Teknologi robotika semakin berkembang dan maju. Robot merupakan karya yang sangat penting bagi kehidupan manusia modern saat ini untuk mempermudah semua pekerjaan manusia. Robot diciptakan untuk menggantikan peran manusia dalam bekerja yang memerlukan kecepatan dan ketepatan. Perkembangan dunia robot saat ini akan difokuskan menjadi robot yang memiliki fitur mirip manusia[2][3]. Bahkan diharapkan memiliki kemampuan berinteraksi dan berperilaku seperti manusia yaitu robot humanoid.
Dunia robotika memasuki berbagai segi di kehidupan manusia mulai dari bidang militer, industri, otomatisasi, entertainment, edukasi maupun juga bidang medis. Humanoid robot adalah salah satu implementasi pada dunia robotika yang dapat menirukan berbagai[4][5].

Kemajuan robotika untuk bergerak layaknya manusia, robot harus memiliki sendi layaknya pada manusia yang dirancang dengan sebuah mekanisme pergerakan yang tersusun dari beberapa bagian secara seri yang terhubung dengan sebuah poros yang bergerak melingkar maupun bergeser yang memiliki derajat kebebasan Degree of Freedom (DOF). Sesuai dengan fungsinya pada robot humanoid persendian ini sangat penting karena menggunakan motor servo sehingga terlihat tampak menyerupai gerakan manusia[6][7]. Berkembangnya dunia robotika perancangan robot kepala ini dirancang untuk menggabungkan cabang ilmu robotika dan computer vision dengan metode yang digunakan beragam untuk mendeteksi 
atau pengenalan objek. Metode yang akan di gunakan adalah Haar Cascade Classifier untuk pendeteksi wajah sebagai objek yang di tangkap oleh kamera dengan gerakan 2 degree of freedom pada motor servo sebagai kendali gerakan kepala untuk mengikuti wajah dengan menggunakan metode Haar Cascade Classifier [8][9].

\section{STUDI PUSTAKA}

\subsection{Raspberry $P i$}

Raspberry pi merupakan sebuah mini pc. Secara fungsional tidak berbeda dengan komputer seperti umumnya, raspberry pi bisa digunakan untuk aktivitas komputer. Raspberry pi membutuhkan daya listrik yang sangat sedikit untuk beroperasi, kelebihan dari raspberry $p i$ terletak pada pin GPIO yang bisa diprogram untuk mengumpulkan data atau mengendalikan modul sensor yang membutuhkan pin sebagai port serial nya[10][11].

Raspberry pi 3 menggunakan sistem operasi berbasis linux dilengkapi dengan menggunakan prosesor ARMoCortex-A53 dari broadcom, dengan spesifikasi 64bit Quad-Core dan berkecepatan 1,2 Ghz dan ram 1 GB serta dilengkapi dengan 4 port USB dan sebuah pengendali Ethernet[12]. Raspberry pi mempunyai slot kartu SDcard. SDcard ini berfungsi sebagai media penyimpanan file-file dan juga sistem operasi yang disimpan dalam kartu $S D$ card.

\subsection{Python}

Bahasa program python merupakan bahasa pemprograman yang interpretatif. Dibandingkan bahasa pemprograman lainnya, python adalah bahasa program yang mudah dipelajari karena merupakan high-level programing. Pemprograman python bersifat multiplatform (bekerja di berbagai platform seperti Windows, Macintosh, Linux, Ubuntu, dan lain sebagainya)[13]. Bahasa pemprograman Python secara umum berbentuk program berorientasi objek, pemprograman imperatif, dan pemrograman fungsional lainnya.

\subsection{Kamera}

Kamera adalah sebuah lensa standar yang dipasang pada papan sirkuit yang digunakan untuk menangkap citra digital. Perangkat ini dapat bermanfaat di bidang telekomunikasi, keamanan dan industri. Untuk melakukan proses akuisisi gambar digunakan sebuah kamera yaitu webcam logitech C270 Full HD kamera webcam ini dapat menangkap gambar dengan resolusi maksimal $1280 \times 720$ piksel atau setara dengan resolusi HD[14][15]. Resolusi tinggi membuat gambar terlihat lebih detail dan cerah. Dengan kelebihannya Webcam Logitech C270 menggunakan lensa beresolusi 3 megapixel, memiliki mikrofon, dan maksimal tampilan gambar mencapai resolusi 720p dengan 30fps .

\subsection{Motor Servo}

Motor servo merupakan motor DC dengan gearbox dan sistem kontrol menggunakan pulsa sebagai penggerak. Sistem kontrol motor servo akan memberikan sinyal pulse ke posisi putaran motor dari $0^{\circ}$ sampai $180^{\circ}[16]$. Motor servo juga memiliki torsi relatif cukup kuat, karena motor servo disusun oleh variabel resistor, gearbox, motor dc dan sistem kendali. 3 kabel yang dimiliki motor servo yaitu kabel power, kabel GND dan kabel data. Kontrol PWM (Pulse Width Modulation) yang diberikan pada motor servo membuat servo dapat bergerak dengan posisi tertentu dan setelah itu berhenti setelah diberi pulse PWM[17].

\subsection{Computer Vision}

Computer Vision merupakan bidang ilmiah yang dapat mengenali objek dari sebuah gambar atau video dengan menggunakan komputer. Arti computer vision adalah teknologi mesin yang dapat melihat, dimana teknologi ini mampu mengekstrak informasi gambar yang ditangkap untuk menyelesaikan tugas tertentu[18]. Sebagai bidang ilmu komputer yang berkaitan dengan data gambar dapat yang diambil, seperti foto, video, pandangan dari kamera real time, atau data dari scanner medis.

\subsection{OpenCV}

OpenCV adalah Open Source Computer Vision merupakan library dari computer vision dibuat oleh perusahaan Intel Corporation yang bersifat terbuka, Kumpulan beberapa bahasa $\mathrm{C}$ dan bahasa $\mathrm{C}++$ pada library OpenCV ini mengimplementasikan semua algoritma computer vision dan juga algoritma image processing[19][20]. Penerapan program OpenCV dalam dunia robotika mempunyai library OpenCV memiliki 2500 lebih algoritma yang sudah dioptimalkan, algoritma dari OpenCV meliputi sebuah himpunan keseluruhan yaitu himpunan klasik dan himpunan seni, beberapa algoritma machine learning dan juga algoritma computer vision.

\subsection{Face Detection}

Face detection merupakan sebuah teknologi dari hasil proses komputer yang digunakan untuk mengidentifikasi wajah seseorang melalui citra digital yang tertangkap oleh kamera. Sistem ini merupakan sebuah tugas utama dari sistem penglihatan manusia yang dengan mudah dilakukan setiap hari, namun kemudahan ini masih sulit untuk sebuah alat yang ingin menyamai seperti kemudahan pada manusia[21][22]. Pendeteksi wajah merupakan satu bentuk dari teknik pengolahan citra dengan mencocokkan bentuk wajah, tekstur wajah maupun banyak hal yang bisa diidentifikasi. Sistem pengenal wajah harus bisa otomatis mendeteksi wajah dalam gambar ini melibatkan ekstrak fitur dan kemudian mengenalinya, terlepas dari pencahayaan, ekspresi, penerangan, penuaan, transformasi (translate, rotate and scale image) dan pose, yang merupakan tugas yang sulit.

Citra digital yang diartikan adalah sebuah gambar wajah seseorang yang berasal dari tangkapan kamera. Secara matematis pengertian citra digital adalah fungsi intensitas cahaya yang terdapat di bidang dua dimensi[23]. Wajah merupakan bagian tubuh terpenting penting dari seseorang dan bagaimana seseorang bisa mengenali orang tersebut. Kecuali dalam kasus kembar identik, wajah ini bisa dibilang karakteristik yang paling unik pada fisik seseorang[24][25].

\section{a. Metode Haar Cascade Classifier}

OpenCV merupakan library computer vision, untuk memudahkan pemprograman pendeteksian wajah, face 
recognition, filtering, face tracking dan juga metode artificial intelligent. OpenCV menggunakan metode haar cascade classifier untuk pemprograman face detector. Metode haar cascade classifier atau bisa juga Haar like feature dikenal sebagai metode bentuk persegi (rectangular), feature yang memberikan bentuk secara detail pada gambar yang ditangkap. Ide pada metode haar cascade classifier ialah pendeteksi objek berdasarkan nilai fitur yang sederhana tetapi bukan dari nilai piksel pada image objek tersebut

Metode ini memiliki sebuah kelebihan tersendiri yaitu komputasi pembacaan objek yang sangat cepat, karena hanya tergantung dari jumlah piksel dalam persegi bukan setiap nilai piksel pada image objek. Metode ini merupakan suatu metode yang menggunakan statistika model (classifier). Pendekatan dari untuk mendeteksi objek pada gambar menggunakan empat cara utama yang diperlukan ialah haar like feature, deep integral image, adaboost, dan cascade classifier.

\section{b. Haar like feature}

Haar feature itu sendiri yaitu fitur yang berdasarkan pada gelombang wavelet haar. Wavelet haar ialah gelombang yang tunggal dengan berbentuk bujur sangkar dengan satu interval rendah dan satu interval tinggi. Untuk objek dua dimensi, yang terdiri dari terang dan gelap, berikutnya kombinasi-kombinasi yang berbentuk kotak yang akan digunakan pada saat pendeteksian objek visual untuk lebih baik. Setiap metode haar like feature memiliki semua kotak putih dan kotak hitam. Fitur pada metode haar ditentukan dengan mengurangkan rata-rata piksel di daerah terang dan rata-rata piksel di daerah gelap. Jika nilai threshold atau nilai ambang terdapat nilai perbedaannya, maka bisa dikatakan kalau fitur tersebut ada. Nilai dari metode haar like feature merupakan perubahan antara jumlah piksel gray level pada daerah kotak putih dan daerah kotak hitam. perhitungan secara cepat pada metode haar like feature menggunakan "deep integral image" agar hasilnya lebih cepat.

c. Deep Integral Image

Deep Integral Image digunakan sebagai penentukan sampel ada atau tidaknya di dalam ratusan fitur dalam sebuah gambar dengan cepat dan dengan skala berbeda secara efisien.

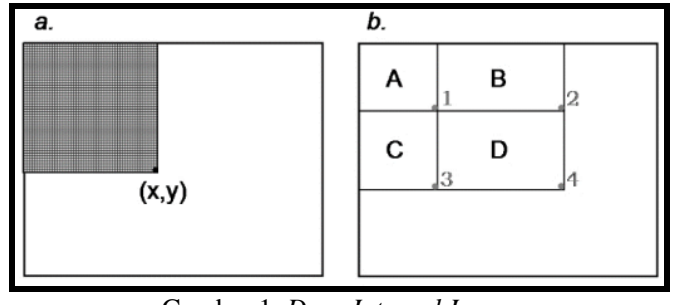

Gambar 1. Deep Integral Image

Seperti pada gambar 1. Bagian a. mengintegrasikan, nilai pada piksel sumbu $(\mathrm{x}, \mathrm{y})$ berisi jumlah semua piksel di dalam daerah segiempat mulai dari kiri atas sampai pada lokasi sumbu (x, y) atau daerah yang diarsir Untuk memperoleh nilai piksel pada daerah yang diarsir (area segiempat) ini hanya bisa dilakukan dengan membagi nilai sumbu $(\mathrm{x}, \mathrm{y})$ pada area yang berbentuk persegi.

$$
i i(x, y)=\sum_{x^{\prime} \leq x, y^{\prime} \leq y} i\left(x^{\prime}, y^{\prime}\right)
$$

Dimana ii sumbu $(x, y)$ merupakan deep integral image dan $i$ sumbu ( $\left.x^{\prime}, y^{\prime}\right)$ adalah original image.

Pada gambar 1. Bagian b. Dari operasi ini, suatu karakteristik dapat diekstraksi dalam waktu yang konstan pada gambar deep integral dengan menambahkan dan mengurangi nilai-nilai simpul untuk setiap persegi panjang. Untuk yang lebih besar kejelasan, pada gambar jumlah piksel yang membentuk persegi panjang D dapat dihitung sebagai

$$
\text { SumD }=(4+1)-(2+3)
$$

Dimana 1, 2, 3, 4, adalah nilai yang diberikan dalam gambar yang terintegrasi di lokasi tersebut.

\section{d. Classifier}

Analisa pada sebuah objek berupa gambar pada tahap Classifier deteksi menetapkan serangkaian karakteristik yang diberikan Ini adalah metode klasifikasi yang menggabungkan beberapa pengklasifikasi dasar untuk membentuk satu lebih kompleks dan akurat Penerapan pengklasifikasi cascade memungkinkan mendapatkan hasil yang baik.

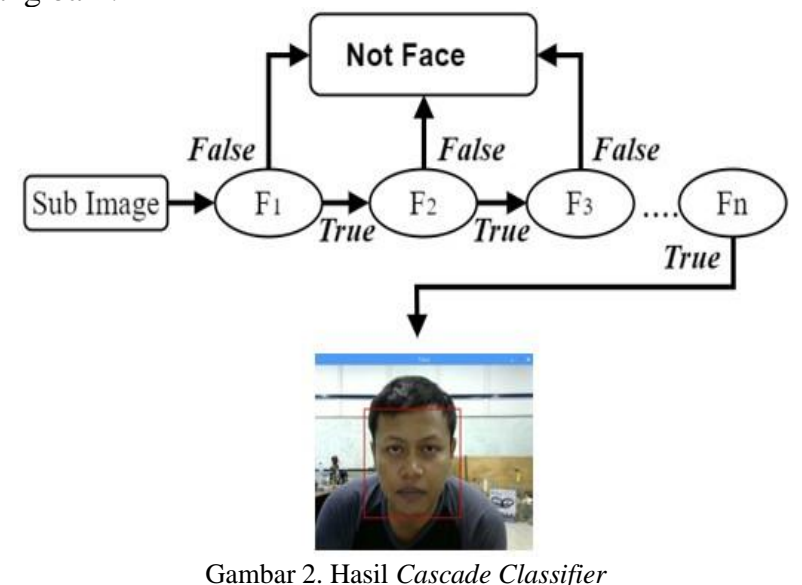

Gambar 2. adalah proses klasifikasi dengan menggunakan cascade classifier, sub image adalah citra gambar yang akan digunakan akan dilakukan deteksi citra melakukan perulangan mencari model wajah sebanyak Fn Proses perulangan dilakukan sebanyak Fn jika bernilai benar maka langsung ditemukan model wajahnya, jika tidak maka proses perulangan akan terus berlanjut sampai dengan Fn.

\section{METODE}

Metode pada penelitian ini akan menjelaskan mengenai proses perancangan dan variabel yang akan diteliti sehingga mempermudahkan penyelesaian tugas akhir.

\subsection{Variabel Penelitian}

Variabel penelitian yang digunakan di penelitian ini adalah gerakan aktuator pada kepala robot dengan sudut putar motor servo pada leher sumbu X $180^{\circ}$ dan sudut putar motor servo pada kepala sumbu Y $60^{\circ}$ mengikuti pergerakan objek yang ditangkap kamera, dan juga pendeteksi wajah menggunakan metode Haar Cascade Classifier menggunakan kamera.

\subsection{Parameter}

Di dalam perancangan pembuatan alat terdapat parameter yang digunakan. Perancangan yang akan diteliti serta 
dianalisis dengan harapan diperoleh data-data mengenai kinerja alat untuk mendeteksi suatu citra digital Jarak merupakan besaran skalar yang mengacu pada panjang objek yang ditangkap oleh kamera dan juga waktu yang dibutuhkan raspberry pi untuk memproses objek citra digital menggunakan sebuah metode haar cascade classifier yang diterapkan pada library OpenCV.

\subsection{Model Arsitektur Skema}

Tugas akhir ini akan dirancang alat robot pendeteksian wajah yang dapat mengikuti gerak objek yang dideteksi oleh kamera dan menggerakkan motor servo agar menyerupai gerakan manusia yang sebenarnya, hasil deteksi kamera akan ditampilkan pada display berupa tampilan kotak pada wajah. Alur bagan perancangan alat ialah sebagai berikut:

1. Kamera digunakan sebagai penangkap citra digital untuk diproses raspberry pi.

2. Raspberry pi bertugas sebagai mini-pc untuk memproses citra digital yang dideteksi dan menggerakkan kepala untuk mengikuti objek.

3. Servo sebagai penggerak kepala untuk mengikuti objek.

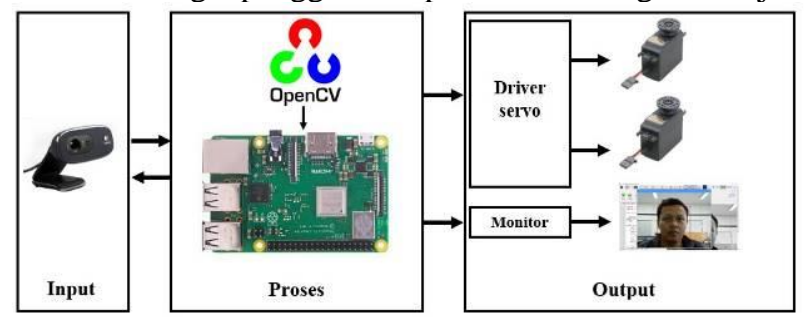

Gambar 3. Bagan Perancangan Kepala Robot

Pada gambar 3 dijelaskan bahwa kamera digunakan untuk mengambil data video real time kemudian raspberry $p i$ memproses hasil citra digital yang ditangkap kamera untuk proses digunakan library open $c v$ yang telah terinstal pada raspberry pi, file video real time yang telah terbaca akan diproses menggunakan metode haar cascade classifier setelah wajah terdeteksi oleh kamera selanjutnya raspberry pi akan mengontrol 2 servo yang akan menjadi aktuator dari kepala robot untuk mengikuti deteksi wajah dan output dari deteksi wajah akan di tampilkan pada monitor

\subsection{Flowchart system}

Flowchart program pada penelitian ini untuk memproses data berupa citra yang ditangkap kamera berupa objek dan proses pada raspberry pi secara real-time. Tampilan flowchart dapat dilihat pada gambar 4. dijelaskan pengkondisian awal sistem dan input yang harus dilakukan pada sensor kamera agar input data berupa citra digital yang dideteksi kamera dapat dibaca oleh raspberry pi dan mini pc adalah kunci untuk memproses data yang dibaca oleh kamera serta memberi keputusan untuk menentukan kamera dapat mengenali wajah atau bukan wajah dan raspberry pi mengontrol motor servo untuk menggerakkan kepala robot humanoid agar mengikuti objek yang ditangkap pada kamera

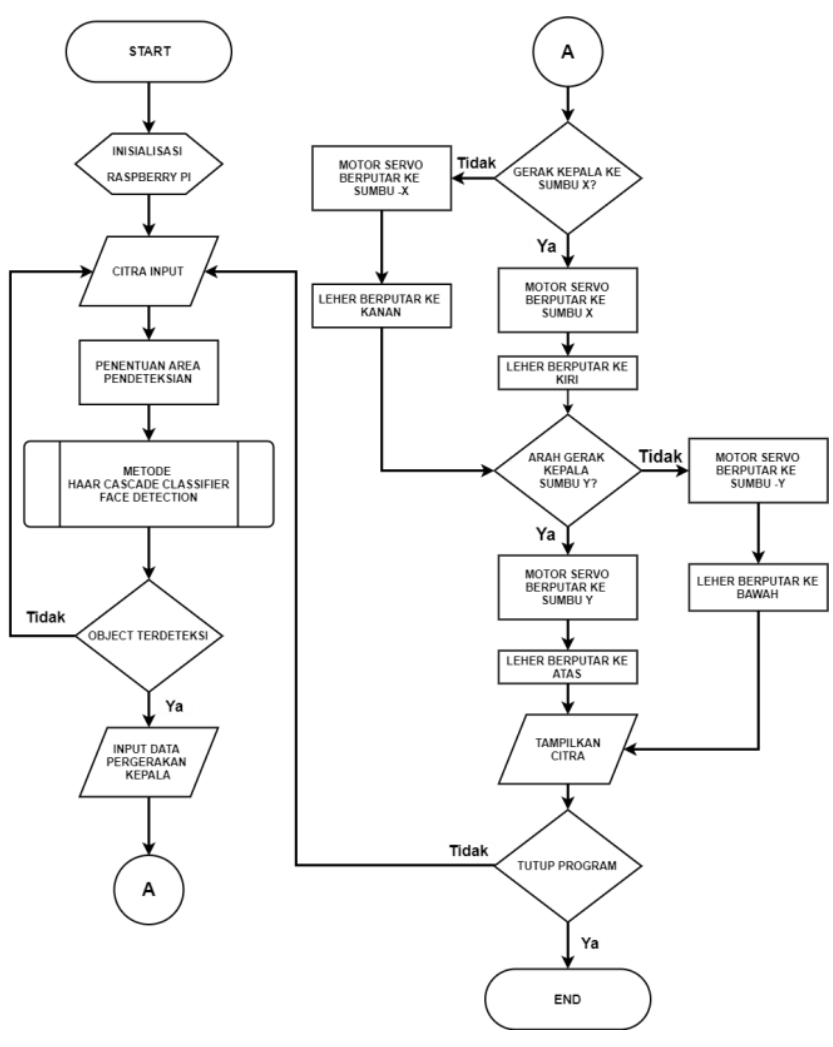

Gambar 4. Flowchart system

3.5. Skematik Rangkaian

Skematik rangkaian yang menghubungkan semua komponen di rancang pada Gambar 3

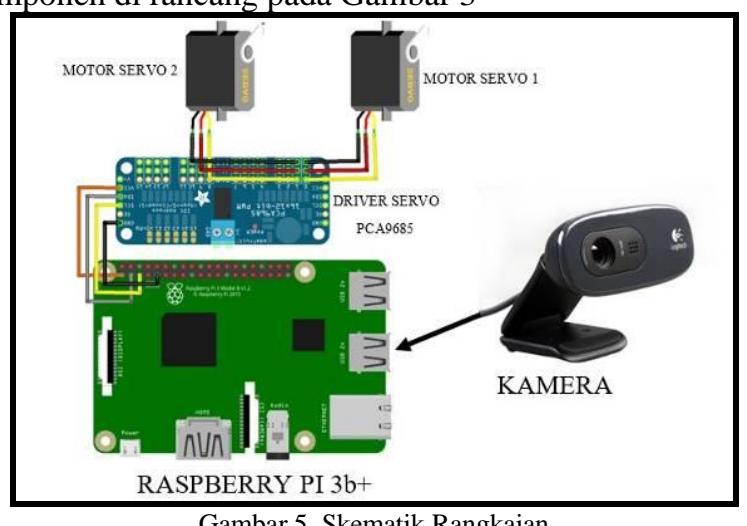

Gambar 5. Skematik Rangkaian

Gambar 5 Menunjukkan perancangan hardware raspberry pi sebagai mini pc, kamera yang dihubungkan pada port USB raspberry pi yang tersedia, driver motor PCA9685 untuk kendali servo yang dihubungkan pada pin GPIO pada raspberry pi dan motor servo untuk penggerak pada kepala robot humanoid yang sudah terpasang pada driver servo PCA9685[26][27].

\section{HASIL DAN PEMBAHASAN}

Pada penelitian ini terdapat Pengujian dan perancangan kepala robot. Pada pengujian pertama yang dilakukan untuk mengetahui proses pendeteksi wajah pada citra digital. Citra diperoleh secara real-time, pengujian kedua dilakukan dengan menguji hasil dari perancangan kepala robot menggunakan motor servo sebagai aktuator.

\subsection{Pengujian citra yang di deteksi kamera}

Langkah awal dalam melakukan deteksi wajah adalah melakukan training data set agar program dapat menyimpan berbagai klasifikasi yang membentuk skema model wajah. 
Selanjutnya adalah kamera akan disiapkan untuk mengambil data kamera secara real time.

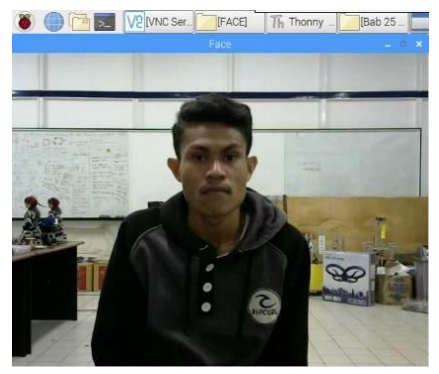

Gambar 6. Data Citra Real Time

Gambar 6. Merupakan contoh data citra real time sebagai input. Untuk melakukan proses deteksi wajah, gambar akan diproses dengan metode deep integral image melakukan perhitungan nilai citra pada empat buah titik dan membuat representasi citra baru.

Selanjutnya nilai yang diperoleh akan diproses menggunakan metode haar like feature dengan menghitung selisih dari jumlah piksel dari daerah di dalam persegi panjang. roses selanjutnya yaitu nilai yang telah diperoleh dari ekstraksi fitur haar akan dibuat sebagai klasifikasi lemah menjadi klasifikasi kuat dengan metode adaboost learning. Setelah didapatkan klasifikasi dengan adaboost learning maka nilai tersebut diproses dengan cascade classifier untuk mengombinasikan banyak fitur. Proses deteksi wajah yang menampilkan citra gambar dan kotak digunakan untuk menunjukkan bahwa wajah telah terdeteksi. Pada gambar 7. Merupakan hasil dari semua proses face detection menggunakan metode haar cascade classifier.

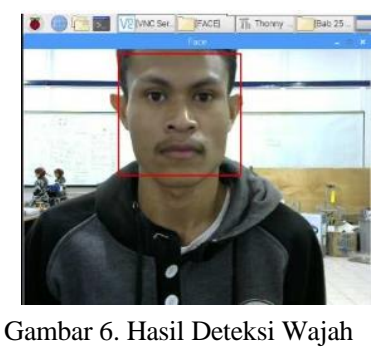

Untuk Pengujian dengan 10 orang yang berbeda di dapatkan hasil yang hampir sama. Penulis melakukan uji coba sistem untuk deteksi wajah dengan ketentuan jarak minimal $100 \mathrm{~cm}$ dan maksimal $300 \mathrm{~cm}$ dengan menghadap ke kepala robot.

Tabel 1. Hasil pengujian sistem pada jarak $100 \mathrm{~cm}$

\begin{tabular}{|c|c|c|c|c|}
\hline \multirow{2}{*}{ No. } & \multirow{2}{*}{ Sample Pengujian } & \multirow{2}{*}{$\begin{array}{c}\text { Waktu } \\
(\mathrm{s})\end{array}$} & Terdeteksi & $\begin{array}{c}\text { Tidak } \\
\text { terdeteksi }\end{array}$ \\
\cline { 4 - 5 } & & & Tingkat Validasi \\
\hline 1 & Mahasiswa ke-1 & 7 & Valid & - \\
\hline 2 & Mahasiswa ke-2 & 7,09 & Valid & - \\
\hline 3 & Mahasiswa ke-3 & 7,34 & Valid & - \\
\hline 4 & Mahasiswa ke-4 & 7,37 & Valid & - \\
\hline 5 & Mahasiswa ke-5 & 7,26 & Valid & - \\
\hline 6 & Mahasiswa ke-6 & 7,13 & Valid & - \\
\hline 7 & Mahasiswa ke-7 & 7,51 & Valid & - \\
\hline 8 & Mahasiswa ke-8 & 7,66 & Valid & - \\
\hline 9 & Mahasiswa ke-9 & 7,67 & Valid & - \\
\hline 10 & Mahasiswa ke-10 & 7,84 & Valid & - \\
\hline
\end{tabular}

Tabel 2. Hasil pengujian sistem pada jarak $200 \mathrm{~cm}$

\begin{tabular}{|c|c|c|c|c|}
\hline \multirow{2}{*}{ No. } & \multirow{2}{*}{ Sample Pengujian } & \multirow{2}{*}{ Waktu(s) } & \multicolumn{2}{|c|}{ Tingkat Validasi } \\
\cline { 4 - 5 } & & 7 & Terdeteksi & $\begin{array}{c}\text { Tidak } \\
\text { terdeteksi }\end{array}$ \\
\hline 1 & Mahasiswa ke-1 & 7 & Valid & - \\
\hline 2 & Mahasiswa ke-2 & 7,85 & Valid & - \\
\hline
\end{tabular}

\begin{tabular}{|c|c|c|c|c|}
\hline \multirow{2}{*}{ No. } & \multirow{2}{*}{ Sample Pengujian } & \multirow{2}{*}{ Waktu(s) } & \multicolumn{2}{|c|}{ Tingkat Validasi } \\
\cline { 4 - 5 } & & & Terdeteksi & $\begin{array}{c}\text { Tidak } \\
\text { terdeteksi }\end{array}$ \\
\hline 3 & Mahasiswa ke-3 & 7,49 & Valid & - \\
\hline 4 & Mahasiswa ke-4 & 7,66 & Valid & - \\
\hline 5 & Mahasiswa ke-5 & 7,33 & Valid & - \\
\hline 6 & Mahasiswa ke-6 & 7,49 & Valid & - \\
\hline 7 & Mahasiswa ke-7 & 7,78 & Valid & - \\
\hline 8 & Mahasiswa ke-8 & 7,73 & Valid & - \\
\hline 9 & Mahasiswa ke-9 & 7,25 & Valid & - \\
\hline 10 & Mahasiswa ke-10 & 8,47 & - & Tidak \\
& & & & Valid \\
\hline
\end{tabular}

Tabel 3. Hasil pengujian sistem pada jarak $300 \mathrm{~cm}$

\begin{tabular}{|c|c|c|c|c|}
\hline \multirow{2}{*}{ No. } & \multirow{2}{*}{ Sample Pengujian } & \multirow{2}{*}{ Waktu(s) } & Terdeteksi & $\begin{array}{c}\text { Tidak } \\
\text { terdeteksi }\end{array}$ \\
\cline { 4 - 5 } & & & Vingkat Validasi & - \\
\hline 1 & Mahasiswa ke-1 & 7,79 & Valid & - \\
\hline 2 & Mahasiswa ke-2 & 7,86 & - & $\begin{array}{c}\text { Tidak } \\
\text { Valid }\end{array}$ \\
\hline 3 & Mahasiswa ke-3 & 8,64 & & - \\
\hline 4 & Mahasiswa ke-4 & 7,96 & Valid & - \\
\hline 5 & Mahasiswa ke-5 & 7,57 & Valid & - \\
\hline 6 & Mahasiswa ke-6 & 8,13 & Valid & - \\
\hline 7 & Mahasiswa ke-7 & 8,11 & Valid & - \\
\hline 8 & Mahasiswa ke-8 & 8,19 & Valid & - \\
\hline 9 & Mahasiswa ke-9 & 8,01 & Valid & Tidak \\
\hline 10 & Mahasiswa ke-10 & 8,55 & - & Valid \\
\hline
\end{tabular}

Tabel1,2,3 merupakan hasil uji deteksi wajah yang akan digunakan untuk pendeteksian kepala robot

4.2. Hasil Perancangan Kepala Robot

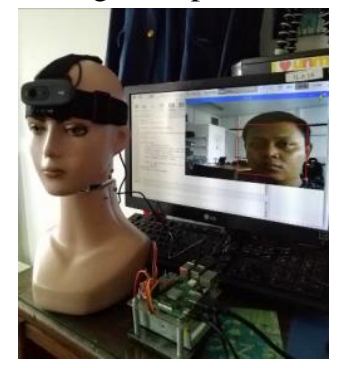

Gambar 7. Hasil Perancangan Kepala Robot

Gambar 7. Merupakan hasil perancangan hardware keseluruhan dari bagian kepala sampai pengontrolnya yang menggunakan raspberry pi. Robot kepala mendeteksi wajah dengan menggunakan aktuator sebagai penggerak untuk mengikuti.

\section{KESIMPULAN}

Berdasarkan pengujian yang dilakukan penulis, penulis dapat menyimpulkan beberapa kesimpulan dari sistem deteksi face detection open cv menggunakan metode haar cascade classifier dan raspberry pi sebagai berikut:

a. Sistem dapa mendeteksi adanya wajah seseorang dengan cepat menggunakan metode haar cascade classifier

b. Spesifikasi kamera yang digunakan akan mempengaruhi akurasi dan kecepatan sistem deteksi, semakin bagus dan semakin tinggi spesifikasi nya, maka semakin tinggi tingkat akurasi nya.

c. sistem mudah untuk melakukan pendeteksian dan pengenalan citra wajah seseorang berdasarkan banyaknya jumlah citra yang di training.

d. Pada waktu 8,55 second rata-rata data citra semuanya tidak terdeteksi dengan benar. 


\section{REFERENSI}

[1] S. Hosseinzadeh, M. Shakeri, and H. Zhang, "Fast Shadow Detection from a Single Image Using a Patched Convolutional Neural Network," in IEEE International Conference on Intelligent Robots and Systems, 2018.

[2] F. J. Chu, R. Xu, and P. A. Vela, "Real-world multiobject, multigrasp detection," IEEE Robot. Autom. Lett., 2018.

[3] D. A. Prasetya, A. Sanusi, G. Chandrarin, E. Roikhah, I. Mujahidin, and R. Arifuddin, "Small and Medium Enterprises Problem and Potential Solutions for Waste Management," J. Southwest Jiaotong Univ., vol. 54, no. 6, 2019.

[4] S. Siswanto, D. A. Prasetya, N. Rachman, and B. F. Hidayatulail, "Pengendali Robot Beroda Berbasis Sensor Telemetri Voice Pattern Recognition,” JASIEK (Jurnal Apl. Sains, Informasi, Elektron. dan Komputer), 2019.

[5] D. A. Prasetya, A. Sanusi, G. Chandrarin, E. Roikhah, I. Mujahidin, and R. Arifuddin, "Community Culture Improvisation Regarding Waste Management Systems and Per Capita Income Increase," J. Southwest Jiaotong Univ., vol. 54, no. 6, 2019.

[6] D. F. C. Kusuma, D. A. Prasetya, F. Kholid, and I. Mujahidin, "Evaluasi Database Senjata Untuk Sistem Keamanan Menggunakan Fuzzy Logic," JASIEK (Jurnal Apl. Sains, Informasi, Elektron. dan Komputer), vol. 1, no. 2, pp. 111-116, 2019.

[7] I. Mujahidin, S. H. Pramono, and A. Muslim, "5.5 Ghz Directional Antenna with 90 Degree Phase Difference Output," 2018.

[8] M. Kalash, M. Rochan, N. Mohammed, N. D. B. Bruce, Y. Wang, and F. Iqbal, "Malware Classification with Deep Convolutional Neural Networks," in 2018 9th IFIP International Conference on New Technologies, Mobility and Security, NTMS 2018 Proceedings, 2018.

[9] I. Mujahidin and P. S. Arinda, "Antena Compact Double Square Marge 2, 6GHz Dengan Output Perbedaan Fase 90 Derajat Untuk Aplikasi LTE," JEECAE (Journal Electr. Electron. Control. Automot. Eng., vol. 4, no. 2, pp. 273-278, 2019.

[10] E. Endrayana, D. H. S. Wahyuni, N. Nachrowie, and I. Mujahidin, "Variasi Ground Plane Antena Collinear Pada Pemancar Telivisi Analog Dengan Frekuensi UHF 442 MHz," JASIEK (Jurnal Apl. Sains, Informasi, Elektron. dan Komputer), vol. 1, no. 2, pp. 149156, 2019.

[11] I. Mujahidin and B. F. Hidayatulail, "2.4 GHz Square Ring Patch With Ring Slot Antenna For Self Injection Locked Radar," JEEMECS (Journal Electr. Eng. Mechatron. Comput. Sci., vol. 2, no. $2,2019$.

[12] B. F. Hidayatulail and I. Mujahidin, "Potential OF 77, $78 \mathrm{~mW}$ Red Diode Laser For Photodynamic," JEEMECS (Journal Electr. Eng. Mechatron. Comput. Sci., vol. 2, no. 2, 2019.

[13] S. K. Sugiarto, I. Mujahidin, and A. B. Setiawan, “2, 5 GHz Antena Mikrostrip Polarisasi Circular Model Patch Yin Yang untuk Wireless Sensor," JEECAE (Journal Electr. Electron. Control. Automot. Eng., vol. 4, no. 2, pp. 297-300, 2019.
[14] S. Kumra and C. Kanan, "Robotic grasp detection using deep convolutional neural networks," in IEEE International Conference on Intelligent Robots and Systems, 2017.

[15] T. A. S, A. Rabi', D. Minggu, and I. Mujahidin, "Frequency Hopping Video Real Time Untuk Pengamanan Data Pengintaian Operasi Inteligence TNI," JASIEK (Jurnal Apl. Sains, Informasi, Elektron. dan Komputer), 2019.

[16] A. E. Pambudi, L. Maajid, J. Rohman, and I. Mujahidin, “Aplikasi Penggunaan Joystick Sebagai Pengendalian Remote Control Weapon Station (Rcws) Senjata Mesin Ringan (SMR)," JASIEK (Jurnal Apl. Sains, Informasi, Elektron. dan Komputer), vol. 1, no. 2, pp. 98-105, 2019.

[17] M. T. Prakarsa, D. Wahyuni, N. Rachman, and I. Mujahidin, "Optimasi Sistem Komunikasi Dari Ht Dengan Hp Dalam Pelaksanaan Tugas Operasi Tni Ad Menggunakan Metode DTMF," JASIEK (Jurnal Apl. Sains, Informasi, Elektron. dan Komputer), 2019

[18] Y. Prayudi and I. Aprizal, "Pemodelan Wajah 3D Berbasis Foto Diri Menggunakan Maya Embedded Language (MEL) Script," Media Inform., 2017.

[19] S. Hutchinson, G. D. Hager, and P. I. Corke, "A tutorial on visual servo control,” IEEE Trans. Robot. Autom., 1996.

[20] M. Wibowo, S. Suprayogi, and I. Mujahidin, "Rancang Bangun Sistem Pengamanan Rak Senjata M16 Menggunakan RFID Dan Fingerprint," JASIEK (Jurnal Apl. Sains, Informasi, Elektron. dan Komputer), vol. 1, no. 2, pp. 134-142, 2019.

[21] Y. Guo, Y. Liu, A. Oerlemans, S. Lao, S. Wu, and M. S. Lew, "Deep learning for visual understanding: A review," Neurocomputing, 2016.

[22] R. Yuwono, I. Mujahidin, A. Mustofa, and Aisah, "Rectifier using UFO microstrip antenna as electromagnetic energy harvester," Adv. Sci. Lett., 2015.

[23] D. Morrison, J. Leitner, and P. Corke, "Closing the Loop for Robotic Grasping: A Real-time, Generative Grasp Synthesis Approach," 2018.

[24] S. Jain, A. Vaibhav, and L. Goyal, "Raspberry Pi based interactive home automation system through E-mail," in ICROIT 2014 Proceedings of the 2014 International Conference on Reliability, Optimization and Information Technology, 2014.

[25]. D A Prasetya, EFA Phong Thanh Nguyen, Rinat Faizullin, Iswanto Iswanto, "Resolving the Shortest Path Problem using the Harversine Algoritm," in Journal of critical reviews 7 (1), 62-64, 2020.

[26]. Zhang, Y., Yasuno, T., D A Prasetya, "Adaptive walking for quadruep robot on irreguler terrain by using CPG network," in 52nd Annual Conference of the Society of Instrument and Control Engineering of Japan, Pages 1734-1737,2013.

[27]. D A Prasetya, T Yusano, "Cooperative control of multiple mobile robot using particle swarm optimization for racking two passive target," in Proceeding of SICE Annual Conference (SICE), 1751$1754,2012$. 